\title{
Global Analysis of SIR Epidemic Model with Immigration and Non-Monotone Incidence Rate under Treatment
}

\author{
D. Jasmine and E.C. Henry Amirtharaj \\ $P G \&$ Research Department of Mathematics, Bishop Heber College, Trichy. Bharathidasan University, India.
}

\begin{abstract}
In this paper we study an epidemic model with immigration and non-monotone incidence rate under limited resources for treatment is proposed to understand the effect of the capacity for treatment. It is assumed that the treatment rate is proportional to the number of patients as long as this number is below a certain capacity and it becomes constant when that number of patients exceeds this capacity. Global analysis is used to study the stability of the disease free equilibrium and endemic equilibrium. It is shown that this kind of treatment rate leads to the existence of multiple endemic equilibria where the basic reproduction number plays a big role in determining this stability.
\end{abstract}

Keywords: Endemic, Global Stability, Non-monotone incidence rate, Reproduction number, Treatment rate.

\section{Introduction}

Mathematical models have become important tools in analysing the spread and control of infectious diseases. The incidence in an epidemiological model is the rate at which susceptible become infectious. The form of the incidence rate that is used in the classical Kermack Mckendrick model (1927) is the simple mass action $\lambda S I$ where $S$ and I denote the number of susceptible and infectious, respectively, $\lambda$ is called the infection coefficient. Many researchers (see Liu et al., 1986, Liu et al., 1987, Hethcote and Levin 1988) have proposed transmission laws in which the nonlinearities are more than quadratic. A more general incidence rate $\lambda I^{p} S=\left(1+\lambda I^{q}\right)$ were proposed by many researchers and authors (see Hethcote and Ven den Driessche 1991). Treatment plays an important role to control or decrease the spread of diseases such as flue, tuberculosis, and measles. In classical epidemic models, the treatment rate is assumed to be proportional to the number of the infectious, which is almost impossible in real perspective because in that case the resources for treatment should be quite large. In fact, every country or society should have a suitable capacity for treatment. If it is too large, the country or society pays for unnecessary cost. If it is too small, the country or society has the risk of the outbreak of a disease. The recent epidemic outbreak of severe acute respiratory syndrome (SARS) had such psychological effects on the general public, aggressive measures and policies, such as border screening, mask wearing, quarantine, isolation, etc. have been proved to be very effective (Diekmann O. et al., 2000, Gumel et al., 2004) in reducing the infective rate at the late stage of the SARS outbreak, even when the number of infective individuals were getting relatively larger. To model this phenomenon, we propose an incidence rate

$$
\mathrm{g}(\mathrm{I}) \mathrm{S}=\frac{\lambda \mathrm{IS}}{1+\alpha \mathrm{I}^{2}}
$$

where $\lambda I$ measures the infection force of the disease and $1 /\left(1+\alpha I^{2}\right)$ describes the psychological or inhibitory effect from the behavioral change of the susceptible individuals when the number of infective individuals is very large. This is important because the number of effective contacts between infective individuals and susceptible individuals decreases at high infective levels due to the quarantine of infective individuals or due to the protection measures by the susceptible individuals. Wang (2006) proposed a treatment function:

$$
\begin{aligned}
T(I) & =r I ; \text { if } 0 \leq I \leq I_{0} \\
& =K_{1} ; \text { if } I>I_{0}
\end{aligned}
$$

where $K_{1}=r I_{0}$. This type of treatment function is more realistic because in every hospital, the number of beds is limited and also they have a certain capacity of medicines. In our proposed model we have considered an epidemic model with non-monotonic incidence rate under the treatment. In our work we take the treatment function $\mathrm{T}(\mathrm{I})$, defined

$$
\begin{aligned}
T(I) & =r I ; \quad \text { if } 0 \leq I \leq I_{0} \\
& =K_{1} ; \text { if } I>I_{0}
\end{aligned}
$$

This means that the treatment rate is proportional to the infective when the number of infective is less or equal to some fixed value $I_{0}$ and the treatment is constant when the number of infective crosses the fixed value $I_{0}$. In practical view, the above form of treatment function is justified where patients have to be hospitalized and the number of beds is limited or the medicines are not sufficient. Xiao and Ruan, 2007 proposed an epidemic model with non-monotonic incidence rate is $\lambda I S /\left(1+\alpha I^{2}\right)$. 
This paper investigates the global analysis of SIR epidemic model with immigration and non-monotone incidence rate under treatment. To construct this model, we will divide the total population into three epidemiological classes which are susceptible (S), infectious (I) and recovered (R).

The proposed model is

\section{The Mathematical Model}

$$
\begin{aligned}
\frac{\mathrm{d} S}{\mathrm{dt}} & =\mathrm{a}-\mathrm{d} \mathrm{S}-\frac{\lambda \mathrm{SI}}{1+\alpha \mathrm{I}^{2}}+\beta \mathrm{R}+\mu \\
\frac{\mathrm{dI}}{\mathrm{dt}} & =\frac{\lambda \mathrm{IS}}{1+\alpha \mathrm{I}^{2}}-(\mathrm{d}+\mathrm{m}) \mathrm{I}-\mathrm{T}(\mathrm{I}) \\
\frac{\mathrm{dR}}{\mathrm{dt}} & =\mathrm{mI}-(\mathrm{d}+\beta) \mathrm{R}+\mathrm{T}(\mathrm{I})
\end{aligned}
$$

where $S(t), I(t)$ and $R(t)$ denote the numbers of susceptible, infective, and recovered individuals at time $t$, respectively. $a$ is the recruitment rate of the population, $d$ is the natural death rate of the population, $\lambda$ is the proportionality constant, $\mathrm{m}$ is the natural recovery rate of the infective individuals, $\beta$ is the rate at which recovered individuals lose immunity and return to the susceptible class, $\mu$ is the increase of susceptible at constant rate, $\alpha$ is the parameter measures the psychological or inhibitory effect.

Case (i) : SIR model with $0 \leq \mathrm{I} \leq \mathrm{I}_{0}$

In this case the system (1)-(3) reduces to

$$
\begin{aligned}
& \frac{\mathrm{dS}}{\mathrm{dt}}=\mathrm{a}-\mathrm{dS}-\frac{\lambda \mathrm{SI}}{1+\alpha \mathrm{I}^{2}}+\beta \mathrm{R}+\mu \\
& \frac{\mathrm{dI}}{\mathrm{dt}}=\frac{\lambda \mathrm{IS}}{1+\alpha \mathrm{I}^{2}}-(\mathrm{d}+\mathrm{m}) \mathrm{I}-\mathrm{rI} \\
& \frac{\mathrm{dR}}{\mathrm{dt}}=\mathrm{mI}-(\mathrm{d}+\beta) \mathrm{R}+\mathrm{rI}
\end{aligned}
$$

The system of equations (4)-(6) always has the disease free equilibrium $E_{0}(a+\mu / d, 0,0)$ for any set of parameter values. The endemic equilibrium is the solution of

$$
\begin{aligned}
& \mathrm{a}-\mathrm{d} \mathrm{S}-\frac{\lambda \mathrm{SI}}{1+\alpha \mathrm{I}^{2}}+\beta \mathrm{R}+\mu=0 \\
& \frac{\lambda \mathrm{IS}}{1+\alpha \mathrm{I}^{2}}-(\mathrm{d}+\mathrm{m}+\mathrm{r}) \mathrm{I}=0 \\
& (\mathrm{~m}+\mathrm{r}) \mathrm{I}-(\mathrm{d}+\beta) \mathrm{R}=0
\end{aligned}
$$

From the third equation, we get

$$
\mathrm{R}=\left[\frac{\mathrm{m}+\mathrm{r}}{\mathrm{d}+\beta}\right] \mathrm{I} \text { and }
$$

From the second equation, we get

$$
\mathrm{S}=\frac{(\mathrm{d}+\mathrm{m}+\mathrm{r})\left(1+\alpha \mathrm{I}^{2}\right)}{\lambda} .
$$

Now substituting $\mathrm{R}$ and $\mathrm{S}$ in the first equation, we get

$$
\begin{aligned}
& {[\alpha \mathrm{d}(\mathrm{d}+\mathrm{m}+\mathrm{r})] \mathrm{I}^{2}+\left[\lambda\left(\mathrm{d}+\mathrm{m}+\mathrm{r}-\frac{\beta(\mathrm{m}+\mathrm{r})}{\mathrm{d}+\beta}\right)\right] \mathrm{I}-\mathrm{d}(\mathrm{d}+\mathrm{m}+\mathrm{r})-\lambda(\mathrm{a}+\mu)=0} \\
& \mathrm{I}=\frac{-\lambda\left[\mathrm{d}+\mathrm{m}+\mathrm{r}-\frac{\beta(\mathrm{m}+\mathrm{r})}{\mathrm{d}+\beta}\right]}{2 \alpha \mathrm{d}(\mathrm{d}+\mathrm{m}+\mathrm{r})}+\sqrt{\frac{\lambda^{2}\left(\mathrm{~d}+\mathrm{m}+\mathrm{r}-\frac{\beta(\mathrm{m}+\mathrm{r})}{\mathrm{d}+\beta}\right)^{2}-4 \alpha \mathrm{d}^{2}(\mathrm{~d}+\mathrm{m}+\mathrm{r})^{2}\left[1-\frac{\lambda(\mathrm{a}+\mu)}{\mathrm{d}(\mathrm{d}+m+r)}\right]}{4 \alpha^{2} \mathrm{~d}^{2}(\mathrm{~d}+\mathrm{m}+\mathrm{r})^{2}}}
\end{aligned}
$$

We define the basic reproduction number as follows

$$
\mathrm{R}_{0}=\frac{\lambda(\mathrm{a}+\mu)}{\mathrm{d}(\mathrm{d}+m+r)}
$$


From equation (7), we see that

(i) If $\mathrm{R}_{0} \leq 1$, then there is no positive equilibrium;

(ii) If $R_{0}>1$, then there is a unique positive equilibrium $E^{*}=\left(S^{*}, I^{*}, R^{*}\right)$, called the endemic equilibrium and is given by

$\mathrm{S}^{*}=\frac{(\mathrm{d}+\mathrm{m}+\mathrm{r})\left(1+\alpha \mathrm{I}^{2}\right)}{\lambda}$

$\mathrm{I}^{*}=\frac{-\lambda\left(\mathrm{d}+\mathrm{m}+\mathrm{r}-\frac{\beta(\mathrm{m}+\mathrm{r})}{\mathrm{d}+\beta}\right)+\sqrt{\Delta}}{2 \alpha \mathrm{d}(\mathrm{d}+\mathrm{m}+\mathrm{r})}$

$\mathrm{R}^{*}=\frac{(\mathrm{m}+\mathrm{r})}{\mathrm{d}+\beta} \mathrm{I}^{*}$

where $\Delta=\lambda^{2}\left(\mathrm{~d}+\mathrm{m}+\mathrm{r}-\frac{\beta(\mathrm{m}+\mathrm{r})}{\mathrm{d}+\beta}\right)^{2}-4 \alpha \mathrm{d}^{2}(\mathrm{~d}+\mathrm{m}+\mathrm{r})^{2}\left[1-\mathrm{R}_{0}\right]$

In the next section, we shall study the property of these equilibria and perform a global qualitative analysis of model (4)-(6).

\section{Mathematical Analysis}

To study the dynamics of model (4)-(6), we first present a lemma.

Lemma : 3.1

The plane $\mathrm{S}+\mathrm{I}+\mathrm{R}=(\mathrm{a}+\mu) / \mathrm{d}$ is an invariant manifold of system (4)-(6), which is attracting in the first octant.

Proof :

Summing up the three equations (4)-(6) and denoting $N(t)=S(t)+I(t)+R(t)$, we have

$\frac{d N}{d t}=\mathrm{a}+\mu-\mathrm{dN}(\mathrm{t})$

$\Rightarrow \mathrm{N}(\mathrm{t})=\mathrm{N}\left(\mathrm{t}_{0}\right)-\frac{\left(\mathrm{a}+\mu-\mathrm{dN}\left(\mathrm{t}_{0}\right)\right) \mathrm{e}^{-\mathrm{d}\left(\mathrm{t}-\mathrm{t}_{0}\right)}}{\mathrm{d}}$

where $\mathrm{N}\left(\mathrm{t}_{0}\right)=A_{1} e^{-d t_{0}}+a+\mu / d$. It is clear that $\mathrm{N}(\mathrm{t}) \rightarrow(\mathrm{a}+\mu) / \mathrm{d}$, as $\mathrm{t} \rightarrow \infty$. So the limit set of system is on the plane $\mathrm{S}+\mathrm{I}+\mathrm{R}=\mathrm{a}+\mu / \mathrm{d}$. Thus the reduced system is

$$
\begin{aligned}
& \frac{\mathrm{dI}}{\mathrm{dt}}=\frac{\lambda \mathrm{I}}{1+\alpha \mathrm{I}^{2}}\left(\frac{\mathrm{a}+\mu}{\mathrm{d}}-\mathrm{I}-\mathrm{R}\right)-(\mathrm{d}+\mathrm{m}+\mathrm{r}) \mathrm{I}=\mathrm{P}(\mathrm{I}, \mathrm{R}) \\
& \frac{\mathrm{dR}}{\mathrm{dt}}=(\mathrm{m}+\mathrm{r}) \mathrm{I}-(\mathrm{d}+\beta) \mathrm{R}=\mathrm{Q}(\mathrm{I}, \mathrm{R})
\end{aligned}
$$

We have the following result regarding the non-existence of periodic orbits in system (12), which implies the non-existence of periodic orbits of system (6) by Lemma.

Theorem : 3.2

Proof :

System (12) does not have nontrivial periodic orbits.

Consider the system (12) for I $>0$ and $\mathrm{R}>0$. Take a Dulac function

$$
\mathrm{D}(\mathrm{I}, \mathrm{R})=\frac{1+\alpha \mathrm{I}^{2}}{\lambda \mathrm{I}}
$$

We have

$$
\frac{\partial(\mathrm{DP})}{\partial \mathrm{I}}+\frac{\partial(\mathrm{DQ})}{\partial \mathrm{R}}=-1-\frac{2 \alpha(\mathrm{d}+\mathrm{m}+\mathrm{r})}{\lambda} \mathrm{I}-\frac{1+\alpha \mathrm{I}^{2}}{\lambda \mathrm{I}}(\mathrm{d}+\beta) \mathrm{R}<0
$$

The conclusion follows. Now to test the local stability of the above system we rescale the system(12) by

$$
\mathrm{x}=\frac{\lambda}{\mathrm{d}+\beta} \mathrm{I}, \mathrm{y}=\frac{\lambda}{\mathrm{d}+\beta} \mathrm{R}, \mathrm{T}=(\mathrm{d}+\beta) \mathrm{t}
$$


Then we obtain

$$
\begin{aligned}
\frac{d x}{d T} & =\frac{x}{1+v x^{2}}(K-x-y)-u x \\
\frac{d y}{d T} & =w x-y
\end{aligned}
$$

where $\mathrm{v}=\frac{\alpha(\mathrm{d}+\beta)^{2}}{\lambda^{2}}, \mathrm{~K}=\frac{(\mathrm{a}+\mu) \lambda}{\mathrm{d}(\mathrm{d}+\beta)}, \mathrm{u}=\frac{\mathrm{d}+m+r}{\mathrm{~d}+\beta}, \mathrm{w}=\frac{\mathrm{m}+\mathrm{r}}{\mathrm{d}+\beta}$.

Here $\mathrm{E}_{0}(0,0)$ is the disease free equilibrium and the unique positive equilibrium $\left(\mathrm{x}^{*}, \mathrm{y}^{*}\right)$ of the system (13)-(14) is the endemic equilibrium $E^{*}$ of the model (4)-(6). $\left(x^{*}, y^{*}\right)$ given by $u v x^{*^{2}}+(1+w) x^{*}+(u-K)=0, y^{*}=w x^{*}$, where

$\mathrm{x}^{*}=\frac{-(1+\mathrm{w})+\sqrt{(1+\mathrm{w})^{2}-4 \mathrm{uv}(\mathrm{u}-\mathrm{K})}}{2 \mathrm{uv}}$

We first determine the stability and topological type of $(0,0)$. The Jacobian matrix of system $(13)$ at $(0,0)$ is

$$
\mathrm{M}_{0}=\left[\begin{array}{cc}
\mathrm{K}-u & 0 \\
\mathrm{w} & -1
\end{array}\right]
$$

If $\mathrm{K}-\mathrm{u}=0$, then there exists a small neighborhood $\mathrm{N}_{0}$ of $(0,0)$ such that the dynamics of system (13) is equivalent to

$$
\begin{aligned}
& \frac{d x}{d T}=-x^{2}-x y+O\left((x, y)^{3}\right) \\
& \frac{d y}{d T}=w x-y
\end{aligned}
$$

We know that $(0,0)$ is a saddle-node. Hence, we obtain the following result.

Theorem : 3.3

The disease-free equilibrium $(0,0)$ of system (14) is

(i) a stable hyperbolic node if $\mathrm{K}-\mathrm{u}<0$,

(ii) a saddle-node if $\mathrm{K}-\mathrm{u}=0$,

(iii) a hyperbolic saddle if $\mathrm{K}-\mathrm{u}>0$.

Proof :

When $\mathrm{K}-\mathrm{u}>0$, we discuss the stability and topological type of the endemic equilibrium $\left(\mathrm{x}^{*}, \mathrm{y}^{*}\right)$. The Jacobian matrix of (13) at $\left(x^{*}, y^{*}\right)$ is

$$
\mathrm{M}_{1}=\left[\begin{array}{cc}
\frac{\mathrm{x}^{*}\left(\mathrm{vx}^{* 2}+2 \mathrm{vwx}^{* 2}-2 \mathrm{Kvx}^{*}-1\right.}{\left(1+\mathrm{vx}^{* 2}\right)^{2}} & \frac{-\mathrm{x}^{*}}{\left(1+\mathrm{vx}^{* 2}\right)^{2}} \\
\mathrm{w} & -1
\end{array}\right]
$$

We have that

$$
\operatorname{det}\left(\mathrm{M}_{1}\right)=\frac{\mathrm{x}^{*}\left(1+\mathrm{w}+2 \mathrm{Kvx}^{*}-(1+\mathrm{w}) \mathrm{vx}^{* 2}\right)}{\left(1+\mathrm{vx}^{* 2}\right)^{2}}
$$

The sign of det $\left(\mathrm{M}_{1}\right)$ is determined by

$$
\mathrm{P}_{1}=\left(1+\mathrm{W}+2 \mathrm{Kvx}^{*}-(1+\mathrm{w}) \mathrm{vx}^{* 2}\right)
$$

Note that $\mathrm{uv} \mathrm{X}^{* 2}+(1+\mathrm{w}) \mathrm{x}^{*}+(\mathrm{u}-\mathrm{K})=0$

We have $\mathrm{uP}_{1}=\left(2 \operatorname{Kuv}+(1+\mathrm{w})^{2}\right)\left[\mathrm{x}^{*}+\frac{(1+\mathrm{w})(2 \mathrm{u}-\mathrm{K})}{2 \mathrm{Kuv}+(1+\mathrm{w})^{2}}\right]$

Now substituting $\mathrm{x}^{*}=\frac{-(1+\mathrm{w})+\Delta_{1}}{2 \mathrm{uv}}$ where $\Delta_{1}=\sqrt{(1+\mathrm{w})^{2}-4 \mathrm{uv}(\mathrm{u}-\mathrm{K})}$, into $\mathrm{P}_{1}$ and using a straightforward calculation, we have 


$$
\mathrm{P}_{1}=-\frac{\Delta_{1}}{2 \mathrm{u}^{2} v}\left[(1+\mathrm{w}) \Delta_{1}-\left[2 \mathrm{Kuv}+(1+\mathrm{w})^{2}\right]\right]=\frac{(1+\mathrm{w}) \Delta_{1}}{2 \mathrm{u}^{2} v}\left[\left(1+\mathrm{w}+\frac{2 \mathrm{Kuv}}{1+w}\right)-\Delta_{1}\right]
$$

Since $\left(1+\mathrm{w}+\frac{2 \mathrm{Kuv}}{1+w}\right)^{2}-\Delta_{1}^{2}=\frac{4 \mathrm{u}^{2} \mathrm{v}^{2} \mathrm{~K}^{2}}{(1+\mathrm{w})^{2}}+4 \mathrm{u}^{2} \mathrm{v}>0$, it follows that $\mathrm{P}_{1}>0$.

Hence, det $\left(M_{1}\right)>0$ and $\left(x^{*}, y^{*}\right)$ is a node or a focus or a center. Furthermore, we have the following result on the stability of $\left(x^{*}, y^{*}\right)$.

Theorem : 3.4

Suppose $\mathrm{K}-\mathrm{u}<0$, then there is a unique endemic equilibrium $\left(\mathrm{x}^{*}, \mathrm{y}^{*}\right)$ of model (14), which is a stable node.

Proof :

We know that the stability of $\left(\mathrm{x}^{*}, \mathrm{y}^{*}\right)$ is determined by trace $\left(\mathrm{M}_{1}\right)$. We have

$$
\operatorname{trace}\left(\mathrm{M}_{1}\right)=\frac{-\mathrm{v}^{2} \mathrm{x}^{* 4}+(1+2 \mathrm{w}) \mathrm{vx^{*3 }}-2(1+\mathrm{K}) \mathrm{vx}{ }^{* 2}-\mathrm{x}^{*}-1}{\left(1+\mathrm{vx}{ }^{* 2}\right)^{2}}
$$

The sign of trace $\left(\mathrm{M}_{1}\right)$ is determined by

$$
\mathrm{P}_{2}=-\mathrm{v}^{2} \mathrm{x}^{* 4}+(1+2 \mathrm{w}) \mathrm{vx}{ }^{* 3}-2(1+K) \mathrm{vx}{ }^{* 2}-\mathrm{x}^{*}-1
$$

We claim that $\mathrm{P}_{2} \neq 0$. To see this, note that $u \mathrm{X}^{* 2}+(1+\mathrm{w}) \mathrm{x}^{*}+\mathrm{u}-\mathrm{K}=0$. Then we have

$\mathrm{u}^{3} \mathrm{vP}_{2}=\left(\mathrm{B}_{1} \mathrm{~K}+\mathrm{B}_{2}\right) \mathrm{x}^{*}-\left(\mathrm{B}_{3} \mathrm{~K}+\mathrm{B}_{4}\right)$, where

$$
\mathrm{P}_{3}=\mathrm{B}_{1} \mathrm{~K}+\mathrm{B}_{2} \text { and } \mathrm{P}_{4}=\mathrm{B}_{3} \mathrm{~K}+\mathrm{B}_{4}
$$

i.e., $\quad P_{3}=(1+w)\left[(1+w)^{2}+u(1+w)(1+2 w)+2 u v K\right]+u^{2} v K(1+2 w)+2 u^{2} v(1+w)(K-u)$

and $\quad \mathrm{P}_{4}=(\mathrm{K}-\mathrm{u})\left[(1+\mathrm{w})^{2}+\mathrm{u}(1+\mathrm{w})(1+2 \mathrm{w})\right]+\mathrm{uv}\left[(\mathrm{K}-\mathrm{u})^{2}+2 \mathrm{u}(\mathrm{K}-\mathrm{u})(1+\mathrm{K})+\mathrm{u}^{2}\right]$

Therefore $\mathrm{P}_{3}$ and $\mathrm{P}_{4}$ are positive for any set of parameters with $\mathrm{K}>\mathrm{u}$. When $\left(\mathrm{x}^{*}, \mathrm{y}^{*}\right)$ exists, the condition for the local stability of $\left(\mathrm{x}^{*}, \mathrm{y}^{*}\right)$ becomes $\mathrm{x}^{*}<\mathrm{P}_{4} / \mathrm{P}_{3}$.

$$
\begin{aligned}
& \mathrm{B}_{1}=\mathrm{uv}(2+3 \mathrm{u}+2 \mathrm{w}+4 \mathrm{uw}), \\
& \mathrm{B}_{2}=(1+\mathrm{w})\left[(1+\mathrm{w})^{2}+\mathrm{u}(1+\mathrm{w})(1+2 \mathrm{w})-2 \mathrm{u}^{3} \mathrm{v}\right], \\
& \mathrm{B}_{3}=-(1+\mathrm{w})^{2}-\mathrm{u}(1+\mathrm{w})(1+2 \mathrm{w})+2 \mathrm{u}^{3} \mathrm{v}, \\
& \mathrm{B}_{4}=\mathrm{u}\left[(1+\mathrm{w})^{2}+\mathrm{u}(1+\mathrm{w})(1+2 \mathrm{w})-\mathrm{v}(1+2 \mathrm{u}) \mathrm{K}^{2}\right] . \\
& -\mathrm{u}
\end{aligned}
$$

When $\mathrm{K}-\mathrm{u}<0$; we can see that $\mathrm{B}_{1} \mathrm{~K}+\mathrm{B}_{2}>0$. Let

Similarly, we have

$$
\xi=u v X^{* 2}+(1+w) x^{*}+u-K \text {. }
$$

$$
\left(\mathrm{B}_{1} \mathrm{~K}+\mathrm{B}_{2}\right)^{2} \xi=\mathrm{u}^{3} \mathrm{vpP}_{2}-\mathrm{P}_{3},
$$

where $\mathrm{p}$ is a polynomial of $\mathrm{x}^{*}$ and

$$
\mathrm{P}_{3}=\mathrm{u}^{3} \mathrm{v}\left(1+\mathrm{K}^{2} \mathrm{v}+2 \mathrm{w}+\mathrm{w}^{2}\right)\left[\left(\mathrm{K}+2 \mathrm{Ku}-2 \mathrm{u}^{2}\right)^{2} \mathrm{v}+(1+\mathrm{K}-\mathrm{u}+\mathrm{w})(1+\mathrm{u}+\mathrm{w}+2 \mathrm{uw})\right] .
$$

Assume that $\mathrm{P}_{2}=0$. Since $\xi=0$, it follows that $\mathrm{P}_{3}=0$. However, when $\mathrm{u}-\mathrm{K}<0$ we have $\mathrm{P}_{3}>0$. Therefore, $\mathrm{P}_{2} \neq$ 0 for any positive value of the parameters $\mathrm{v}, \mathrm{w}$ and $\mathrm{K}$, that is,

trace $\left(\mathrm{M}_{1}\right) \neq 0$. Thus, $\mathrm{u}-\mathrm{K}<0$ implies that $\left(\mathrm{x}^{*}, \mathrm{y}^{*}\right)$ does not change stability.

Take $\mathrm{u}=1, \mathrm{~K}=2, \mathrm{v}=1, \mathrm{w}=1$. Then $\mathrm{x}^{*}=-1+\sqrt{2}, \mathrm{y}^{*}=-1+\sqrt{2}$,

Trace $\left(\mathrm{M}_{1}\right)=-1.4645<0$.

By the continuity of trace $\left(\mathrm{M}_{1}\right)$ on the parameters, we know that trace $\left(\mathrm{M}_{1}\right)<0$ for $\mathrm{u}-\mathrm{K}<0$. This completes the proof.

Theorem : 3.5

(i) When the basic reproduction number $R_{0} \leq 1$, there exist no positive equilibrium of the system (14)-(15), and in that case the only disease free equilibrium $(0,0)$ is a stable node.

(ii) When $R_{0}>1$, there exists a unique positive equilibrium of the system (14)-(15), and in that case $(0,0)$ is an unstable saddle point. Also the condition for which the unique positive equilibrium will be locally stable if $x^{*}<P_{4} / P_{3}$. 
Theorem : 3.6

If $R_{0}<1$, then the disease free equilibrium $E_{0}(a / d, 0,0)$ of the system (12)-(13) is globally stable. But when $R_{0}>1$, system (12)-(13) has unique positive equilibrium and further when $x^{*}<P_{4} / P_{3}$ that unique positive equilibrium must be locally stable. Again since the system has no limit cycle in the positive quadrant, $E^{*}\left(x^{*}, y^{*}\right)$ must be globally stable under the condition $R_{0}>1$ and $x^{*}<P_{4} / P_{3}$.

Theorem : 3.7

Let $\mathrm{R}_{0}$ be defined by (8).

(i) If $\mathrm{R}_{0}<1$, then model (6) has a unique disease-free equilibrium $\mathrm{E}_{0}=((\mathrm{a}+\mu) / \mathrm{d}, 0,0)$, which is a global attractor in the first octant.

(ii) If $\mathrm{R}_{0}=1$, then model (6) has a unique disease-free equilibrium $\mathrm{E}_{0}=((\mathrm{a}+\mu) / \mathrm{d}, 0,0)$, which attracts all orbits in the interior of the first octant.

(iii) If $\mathrm{R}_{0}>1$, then model (6) has two equilibria, a disease-free equilibrium $\mathrm{E}_{0}=((\mathrm{a}+\mu) / \mathrm{d}, 0,0)$, and an endemic equilibrium $\mathrm{E}^{*}=\left(\mathrm{S}^{*}, \mathrm{I}^{*}, \mathrm{R}^{*}\right)$. The endemic equilibrium $\mathrm{E}^{*}$ is a global attractor in the interior of the first octant.

Case (ii) : SIR model with $\mathrm{I}>\mathrm{I}_{0}$

In this case the model is

$$
\begin{aligned}
& \frac{d s}{d t}=a-d s-\frac{\lambda I S}{1+\alpha I^{2}}+\beta R+\mu \\
& \frac{d I}{d t}=\frac{\lambda I S}{1+\alpha I^{2}}-(d+m) I-K_{1} \\
& \frac{d R}{d t}=m I-(d+\beta) R+K_{1}
\end{aligned}
$$

Since $S+I+R=\frac{a+\mu}{d}$ is invariant manifold of the system (22)-(24), the model reduces to

$$
\begin{aligned}
& \frac{d I}{d t}=\frac{\left.\lambda I\left[\frac{a+\mu}{d}-I-R\right)\right]}{1+\alpha I^{2}}-(d+m) I-K_{1} \\
& \frac{d R}{d t}=m I-(d+\beta) R+K_{1}
\end{aligned}
$$

Substituting $x=\frac{\lambda I}{d+\beta}, y=\frac{\lambda R}{d+\beta}$ and $T=(d+\beta) t$ we get

$$
\frac{d x}{d T}=\frac{x(K-x-y)}{1+v_{1} x^{2}}(K-x-y)-u_{1} x-c
$$

$$
\frac{d y}{d T}=w_{1} x-y-c
$$

where $K=\frac{\lambda(a+\mu)}{d(d+\beta)}, u_{1}=\frac{d+m}{d+\beta}, v_{1}=v=\frac{\alpha(d+\beta)^{2}}{\lambda^{2}}, c=\frac{\lambda K_{1}}{(d+\beta)^{2}}, w_{1}=\frac{m}{d+\beta}$

For the equilibrium, put

$$
\begin{aligned}
& x(K-x-y)-u_{1} x\left(1+v_{1} x^{2}\right)-c\left(1+v_{1} x^{2}\right)=0 \\
& u_{1} v x^{3}+\left(1+w_{1}+c v\right) x^{2}+\left(c+u_{1}-K\right) x+c=0
\end{aligned}
$$

If $u_{1}+c>K$, equation (28) has no positive solution. But if $u_{1}+c<K$, then it has either two positive roots or no positive root. By the theory of equations 


$$
p_{0} x^{3}+3 p_{1} x^{2}+3 p_{2} x+p_{3}=0
$$

has all roots are real if the conditions $G^{2}+4 H^{3}<0$ and $H<0$, where

$$
H=p_{0} p_{2}-p_{1}^{2} \text { and } G=p_{0}{ }^{2} p_{3}-3 p_{0} p_{1} p_{2}+2 p_{1}^{3} \text { are satisfied. }
$$

Comparing equation (28) and (29) we have

$$
\begin{aligned}
& \mathrm{p}_{0}=\mathrm{u}_{1} \mathrm{v}, \quad \mathrm{p}_{1}=\left(1+\mathrm{w}_{1}+\mathrm{cv}\right) / 3, \quad \mathrm{p}_{2}=\left(\mathrm{u}_{1}+\mathrm{c}-\mathrm{K}\right) / 3 \text { and } \mathrm{H}<0 \\
& H=p_{0} p_{2}-p_{1}^{2}=u_{1} v\left[\left(u_{1}+c-K\right) / 3\right]-\left[\left(1+w_{1}+c v\right) / 3\right]^{2}<0, \text { for }_{1}+c<K
\end{aligned}
$$

When $u_{1}+c<K$ then $H<0$ and

$$
\begin{aligned}
G^{2}+4 H^{3} & =\left(p_{0}{ }^{2} p_{3}-3 p_{0} p_{1} p_{2}+2 p_{1}^{3}\right)^{2}+4\left(p_{0} p_{2}-p_{1}{ }^{2}\right)^{3} \\
& =p_{0}{ }^{2}\left(p_{0}{ }^{2} p_{3}{ }^{2}-6 p_{0} p_{1} p_{2} p_{3}+4 p_{3} p_{1}^{3}+4 p_{0} p_{2}^{3}-3 p_{1}{ }^{2} p_{2}{ }^{2}\right)
\end{aligned}
$$

To fulfill the condition $G^{2}+4 H^{3}<0$ we must have

$$
\left(p_{0}^{2} p_{3}^{2}+4 p_{3} p_{1}^{3}+4 p_{0} p_{2}^{3}\right)<\left(3 p_{1}^{2} p_{2}^{2}+6 p_{0} p_{1} p_{2} p_{3}\right)
$$

To investigate the local stability of the positive equilibrium $(x, y)$ of the system (26) - (27), we consider the Jacobian matrix

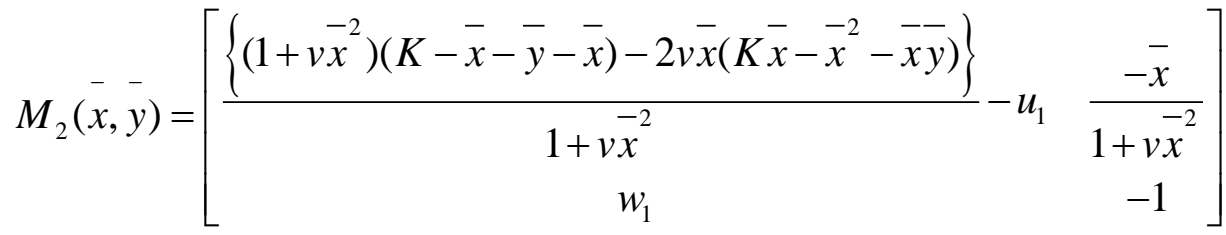

Now $\operatorname{det}\left(\mathrm{M}_{2}\right)=\frac{1}{\left(1+v \bar{x}^{2}\right)^{2}}\left\{\begin{array}{l}-\left(1+v \bar{x}^{2}\right)\left(K-2 \bar{x}-w_{1} \bar{x}-c\right)+2 v \bar{x}\left(K \bar{x}-\bar{x}^{2}-w_{1} \bar{x}^{2}-c \bar{x}\right) \\ +u_{1}\left(1+v \bar{x}^{2}\right)^{2}+w_{1} \bar{x}\left(1+v \bar{x}^{2}\right)\end{array}\right\}$

Solving this we get the sign of the $\operatorname{det}\left(\mathrm{M}_{2}\right)$ is governed by the factor

$$
P_{5}=-v\left(1+w_{1}+c v\right) \bar{x}^{3}+v\left(2 K+u_{1}-2 c\right) \bar{x}^{2}+\left(2+2 w_{1}-v c\right) \bar{x}+\left(c+u_{1}-K\right)
$$

We recall equation (28) and use it in (31). After some calculations we get,

$$
\begin{aligned}
& u_{1} P_{5}=\bar{x}^{2}\left[2 K u_{1} v+u_{1}^{2} v-2 u_{1} v c+\left(1+w_{1}+c v\right)^{2}\right]+\bar{x}\left[\left(2 u_{1}+2 u_{1} w_{1}-u_{1} v c\right)+\left(1+w_{1}+c v\right)\left(u_{1}+c-K\right)\right]+ \\
& {\left[\left(c u_{1}+u_{1}^{2}-K u_{1}\right)+c\left(1+w_{1}+c v\right)\right]} \\
& \therefore u_{1} P_{5}=\xi_{1} \bar{x}^{2}+\xi_{2} \bar{x}+\xi_{3}
\end{aligned}
$$

where $\xi_{1}=\left\{u_{1}^{2} v+\left(1+w_{1}+c v\right)^{2}+2 u_{1} v(K-c)\right\}>0$ for $K>c$.

i.e., $\xi_{1}>0$ if $K<c$

Hence with the above condition, sufficient condition for $\mathrm{p}_{5}$ to be positive if $\xi_{2}^{2}-4 \xi_{1} \xi_{2} \leq 0$

$\operatorname{Trace}\left(\mathrm{M}_{2}\right)=\frac{\left\{\left(1+v \bar{x}^{2}\right)\left(K-2 \bar{x}-w_{1} \bar{x}-c\right)-2 \bar{x}^{2}\left(K-\bar{x}-w_{1} \bar{x}-c\right)\right\}-\left(u_{1}+1\right)\left(1+v \bar{x}^{2}\right)^{2}}{\left(1+v \bar{x}^{2}\right)^{2}}$

Solving this we get the sign of Trace $\left(\mathrm{M}_{2}\right)$ is determined by the sign of

$$
P_{6}=-\left(u_{1}+1\right) v^{2} \bar{x}^{4}+v w_{1} \bar{x}^{-3}+\left(v c-K v-2 v u_{1}-2 v\right) \bar{x}^{-2}-\left(2+w_{1}\right) \bar{x}+\left(K-c-u_{1}-1\right)
$$

After some algebraic calculation using (28) and (34) we get

$$
\begin{gathered}
u_{1}^{2} P_{6}=\eta_{1} \bar{x}^{2}+\eta_{2} \bar{x}+\eta_{3} \\
\eta_{1}=-\left[\left(1+w_{1}+c v\right)\left(2 u_{1} w_{1}+u_{1} c v+u_{1}+w_{1}+c v+1\right)+u_{1} v(K-c)\left(1+2 u_{1}\right)+u_{1}^{2}+u_{1}\right]<0
\end{gathered}
$$


for $K>u_{1}+c$,

$$
\begin{aligned}
& \eta_{2}=u_{1}\left(c v u_{1}+c v-2 u_{1}-w_{1} u_{1}\right)-\left(u_{1}+c-K\right)\left(2 u_{1} w_{1}+u_{1} c v+u_{1}+w_{1}+c v+1\right), \\
& \eta_{3}=u_{1}\left(K-c-u_{1}-1\right)-c\left(2 u_{1} w_{1}+u_{1} c v+u_{1}+w_{1}+c v+1\right) .
\end{aligned}
$$

Therefore the sufficient condition for which $P_{6}<0$ is

$$
\eta_{2}^{2}-4 \eta_{1} \eta_{3} \leq 0
$$

We conclude the above finding in the following theorem.

Theorem : 3.8

When $K>u_{1}+c$, the system (26)-(27) has two positive equilibrium points $\left(\bar{x}_{1}, \bar{y}_{1}\right)$ and $\left(\bar{x}_{2}, \bar{y}_{2}\right)$, where $\bar{x}_{1}$ and $\bar{x}_{2}$ are the solution of the equation (28) under the parametric conditions given by (30) and when the conditions (33) and (35) are fulfilled at some equilibrium point, that point must be asymptotically stable.

Case (i) :

\section{Numerical Simulation and Discussion} follows.

When the treatment rate is $\infty$ to the infective so that $0 \leq \mathrm{I} \leq \mathrm{I}_{0}$. We choose the parameters in the model as $\mathrm{a}=4, \mathrm{~d}=0.2, \alpha=0.2, \beta=0.2, \lambda=0.3, \mu=0.2, \mathrm{~m}=0.02, \mathrm{r}=0.3$ and $\alpha$ varies from 0 to 4

Here the basic reproduction number $\mathrm{R}_{0}=12.12>1$. The equilibrium position goes lower and when the new parameter $\alpha$ increases. Simultaneously when we increase the treatment function $r$ we see that at $\alpha=4$ and $r$ $=1.5$ susceptible population increases significantly.

When $\alpha=3, a=25, \beta=0.2, d=5, m=20, r=0.2, \mu=0.2, \lambda=0.5$ we have $\mathrm{R}_{0}=0.1<1$. In this case the disease dies out. Consider the values of the parameters

$$
\mathrm{a}=4, \mathrm{~d}=0.2, \alpha=0.2, \beta=0.2, \mu=0.2, \lambda=0.3, \mathrm{~m}=0.02, \mathrm{r}=0.3
$$

By rescaling the system we see that $\mathrm{u}-\mathrm{K}<0$ hence there exists the unique positive equilibrium $\mathrm{x}=3.9573$ and $y^{*}=3.1658$. For the above parameters $P_{4} / P_{3}=28.8216$ and therefore then sufficient condition for stability $x^{*}<P_{4} / P_{3}$ is satisfied. Hence the point is locally stable.

Case (ii) :

When $\mathrm{I}>\mathrm{I}_{0}$, the parameters are

$$
\mathrm{a}=3, \mathrm{~d}=0.1, \alpha=2, \beta=0.1, \lambda=0.3, \mathrm{~m}=0.02, \mathrm{~K}_{1}=0.7, \mu=0.1, \mathrm{r}=0.3
$$

In this case $S+I+R=a+\mu / d=31$ is invariant manifold. The system reduces to

$$
\begin{aligned}
& \frac{d I}{d t}=\frac{0.3 I(31-I-R)}{1+2 I^{2}}-0.12 I-0.7 \\
& \frac{d R}{d t}=0.02 I-0.2 R+0.7
\end{aligned}
$$

The rescaling system reduces to

$$
\begin{aligned}
& \frac{d x}{d T}=\frac{x(46.5-x-y)}{1+0.889 x^{2}}(46.5-x-y)-0.6 x-0.525 \\
& \frac{d y}{d T}=0.1 x-y+o .525
\end{aligned}
$$

Here $K-u>0$ and hence there exists unique positive equilibrium point $\left(\mathrm{x}^{*}, \mathrm{y}^{*}\right)$ where $\mathrm{x}^{*}=62.6970$ and $\mathrm{y}^{*}=131.664$. For the above choice of parameters $P_{3}=100.431>0, P_{4}=540.765, P_{4} / P_{3}=5.384$ and therefore the sufficient condition for local stability. i.e., $\mathrm{x} * P_{4} / P_{3}$ is satisfied.

In order to see the equilibrium point we have $\mathrm{u}_{1}+\mathrm{c}<\mathrm{K}-\mathrm{cv}$ and $\mathrm{u}_{1} \mathrm{v}<\mathrm{cv}$. Thus the above equation has two positive roots. It can be easily calculated that increasing values of $\alpha$ slightly lowers down $\left(\mathrm{x}_{1}, \mathrm{y}_{1}\right)$ whereas pushes up the pair $\left(\mathrm{x}_{2}, \mathrm{y}_{2}\right)$. 


\section{Graphical Representation}

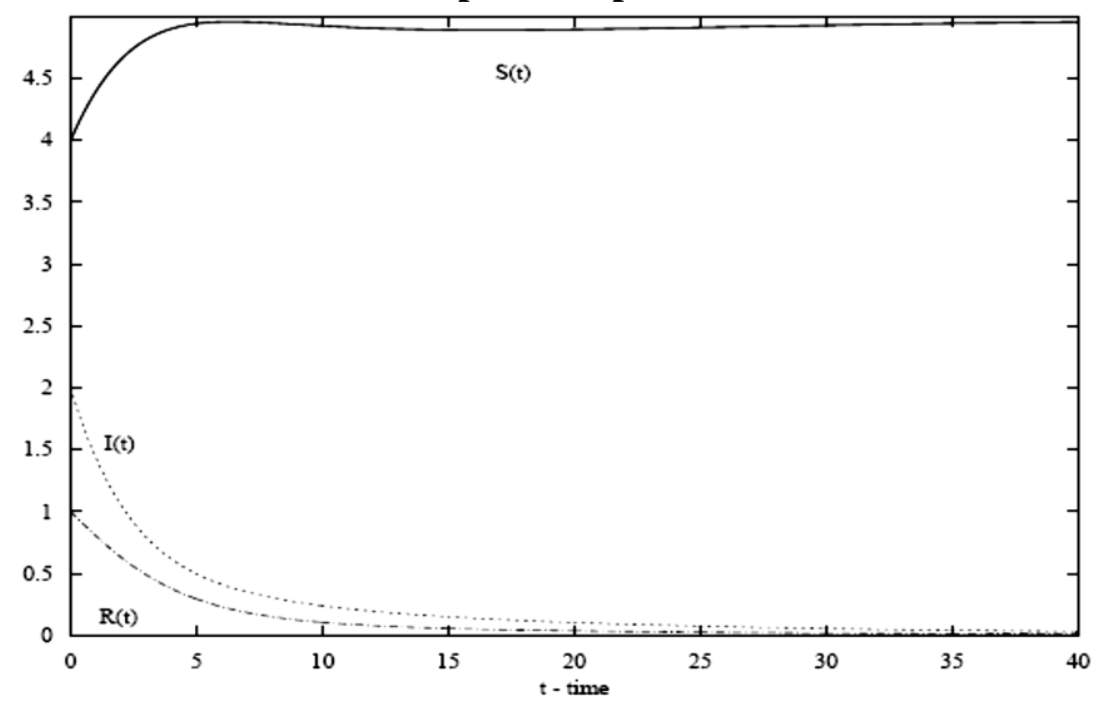

Figure 1

When $\mathrm{a}+\mu=25.2, \mathrm{~d}=5, \lambda=0.5, \alpha=3, \beta=0.2, \mathrm{~m}=20, \mathrm{r}=0.2, \mathrm{R}_{0}=0.1<1, \mathrm{~S}(\mathrm{t})$ approaches to its steady state value while $I(t)$ and $R(t)$ approach zero as time goes to infinity, the disease dies out. Here we proposed a non-monotone incidence rate of the form $\lambda \mathrm{IS}=\left(1+\alpha \mathrm{I}^{2}\right)$, which is increasing when $\mathrm{I}$ is small and decreasing when I is large. It can be used to interpret the "psychological" effect: the number of effective contacts between infective individuals and susceptible individual decreases at high infective levels due to the quarantine of infective individuals or the protection measures by the susceptible individuals. The recent epidemic outbreak of severe acute respiratory syndrome (SARS) had such psychological effects on the general public.

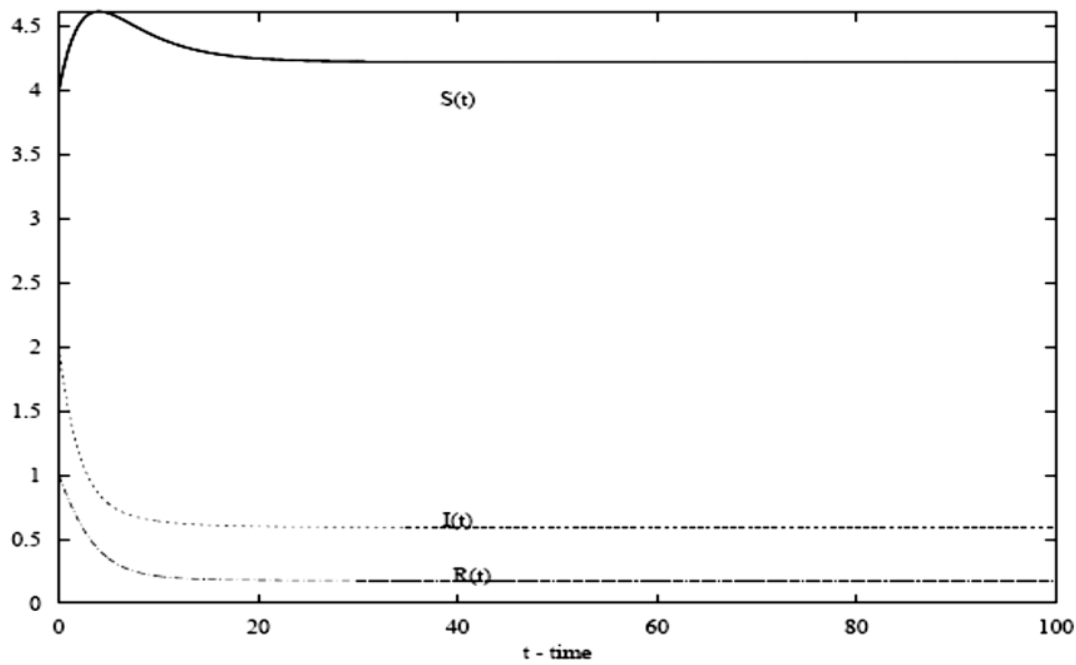

Figure 2

When $\mathrm{a}+\mu=4.2, \mathrm{~d}=0.2, \lambda=0.3, \alpha=0.2, \beta=0.2, \mathrm{~m}=0.02, \mathrm{r}=0.3, \mathrm{R}_{0}=12.12>1$, all three components, $\mathrm{S}(\mathrm{t}), \mathrm{I}(\mathrm{t})$ and $\mathrm{R}(\mathrm{t})$, approach to their steady state values as time goes to infinity, the disease becomes endemic. We have carried out a global qualitative analysis of an SIR model with this non-monotone and nonlinear incidence rate and studied the existence and stability of the disease-free and endemic equilibria. It indicates that when $R_{0}<1$, the disease-free equilibrium is globally attractive (see Figure 1). When $R_{0}>1$, the endemic equilibrium exists and is globally stable (see Figure 2). 


\section{Concluding Remarks}

SIR Epidemic model with non-monotone incidence rate describes the psychological effect of certain serious diseases on the community when the number of infective is getting larger. By carrying out a global analysis of the model and studying the stability of the disease-free equilibrium and the endemic equilibrium, we show that either the number of infective individuals tends to zero as time evolves or the disease persists. In this paper we see that the basic reproductive number plays an important role to control the disease. When $\mathrm{R}_{0} \leq 1$, there exists no positive equilibrium, and in that case the disease free equilibrium is globally stable, that is the disease dies out. But when $\mathrm{R}_{0}>1$, the unique endemic equilibrium is globally stable under some parametric condition. Also we see that the treatment rate plays a major role to control the disease. When $\mu=0$, the model coincides with that of Gajendra. et. al. .

The stability of the disease-free equilibrium and the endemic equilibrium, we show that either the number of infective individuals tends to zero as time evolves or the disease persists. From this model, the basic reproductive number $\mathrm{R}_{0}$ has been introduced though the basic reproductive number $\mathrm{R}_{0}$ does not depend on $\alpha$ explicitly, numerical simulations indicate that when the disease is endemic, $\mathrm{I}^{*}$ of the infective decreases as $\alpha$ increases. From (10) we see that $\mathrm{I}^{*}$ approaches zero as $\alpha$ tends to infinity.

\section{References}

[1] Alexander M.E. and Moghadas S.M. (2004). Periodicity in an epidemic model with a generalized non-linear incidence, J.Math. Biosci., 189, 75-96.

[2] Capasso V. and Serio G., (1978), A Generalization of the Kermack-Mckendrick Deterministic Epidemic model, J.Math. Biosci. 42, 43-61.

[3] Derrick W. R. and Van den Driessche P., (1993), A disease transmission model in a non constant population., J. Math. Biol., 31, 495-512.

[4] Esteva L. and Matias M., (2001), A model for vector transmitted diseases with saturation incidence, Journal of Biological Systems, 9(4), 235-245.

[5] Hethcote H.W. and Van den Driessche P., (1991), Some epidemiological models with non-linear incidence, J. math. Boil., 29, 271287.9 .

[6] Jasmine D. and Henry Amirtharaj E.C., (2013), Modeling and Stimulation of Modified SIR Epidemic Model with Immigration and Non-monotonic Incidence Rate under Treatment, Indian Journal of Applied Research, 3(7), 43-44.

[7] Jasmine D. and Henry Amirtharaj E.C.,(2013), Global Analysis of SIR Epidemic Model with Immigration and Non-Monotone Incidence Rate, International Journal of Applied Research and Statistical Sciences, Vol. 2(5)., 83-92.

[8] Leung G. M., The impact of community psychological response on outbreak control for severe acute respiratory syndrome in Hong Kong, J. Epidemiol. Community Health, 57 (2003), 857-863.

[9] Liu W. M., Hethcote H. W. and Levin S., (1987), A. Dynamical Behavior of Epidemiological Models with Nonlinear Incidence Rates, J. Math. Biol., 25, 359-380.

[10] Liu W.M., Levin S.A., and Iwasa Y., (1986), Influence of Nonlinear Incidence Rates upon the Behavior of SIRS Epidemiological Models, J. Math. Biol., 187-204.

[11] Wang W. and Ruan S., (2003), Dynamical behavior of an epidemic model with nonlinear incidence rate, J. Differential equations, $188,135-163$

[12] Xiao D. and Ruan S., (2007), Global analysis of an epidemic model with non monotone incidence rate, Math. Biosci. 208, 419-429.

[13] Diekmann O. and Heesterbeek J.A., Mathematical Epidemiology of Infectious Diseases Model building analysis and interpretation, New york, John Wiley \& Sons, Incorporated, 2000.

[14] Dongmei Xiao and Shigui Ruan, Global Analysis of an Epidemic Model with Non-monotone Incidence Rate, University of Miami.

[15] Hethcote H.W. and Levin S.A., (1988), Periodicity in epidemiological models. In mathematical Ecology, volume II, ed. By Levin S.A., Hallam T.G. and Gross L. Springer Verlag, New york.

[16] Perko L., Differential Equations and Dynamical Systems, Springer-Verlag, New York,1996.

[17] Gumel A. B., Modelling strategies for controlling SARS outbreaks, Proc. R. Soc.Lond. B 271 (2004), $2223-2232$. 